\title{
Development of gasification agent injection tool for underground coal gasification
}

\author{
Zhi Chen ${ }^{1, a}$, Feng Zhu ${ }^{1}$, Youjun Zhang ${ }^{1}$, Weiping $\mathrm{Lv}^{1}$ and Zheng Zhang ${ }^{1}$ \\ ${ }^{1}$ Jianghan Machinery Research Institute Limited Company of CNPC, Wuhan City, Hubei Province, China
}

\begin{abstract}
The underground coal gasification (UCG) technology is basically mature, but the influence of its own process and tools slows down its industrialization progress. This paper introduced the development and field test of two new UCG coiled-tubing gasification agent injection tools. The test results show that the two kinds of gasification agent injection tools ensure the injection point under control by conducting downhole temperature measurement and ground monitoring jointly. The problem that the tool is burnt by the backfire is solved by designing a backfire prevention device. To realize low pressure drop, the gasification agent flow channel inside the tool is designed optimally to keep the tool pressure drop not more than $0.5 \mathrm{MPa}$ and the system pressure drop not more than $3 \mathrm{MPa}$. The tool overall has the characteristics of low pressure drop, high temperature resistance, backfire prevention and anti burning to satisfy the demand of the field test. This technology is a new achievement in the development of UCG technology and equipment in China. The research conclusions can provide technical reference for developing a new generation of UCG technology.
\end{abstract}

\section{Introduction}

Underground coal gasification (UCG) is a process of controlled combustion of underground coal to produce combustible gas through thermal and chemical action of coal. It integrates well construction, coal mining and gasification, changing traditional physical coal mining into chemical coal mining. It has following technical advantages: (1) high efficiency, it can recover abandoned coal resources of old mines, mine low-grade, difficult to mine and deep coal resources, and the resource utilization rate is increased from $15 \%$ to $50 \%$ of the underground method to $70 \%$ to $90 \%$; (2) safety, it realizes underground unmanned production, avoids personal injury and various mine accidents; (3) environmental protection, gangue and ash remain underground, reducing surface collapse. Underground coal gasification is of great strategic significance to the development of China's natural gas industry by using underground coal resources to produce methane and hydrogen in view of the occurrence characteristics of "rich coal but less oil and gas" resources in China. Through the industrial chain of "underground coal gasification, petrochemical refinery hydrogen, $\mathrm{CO}_{2}$ enhanced crude oil recovery and storage", we can make clean use of coal resources, ease the tension of natural gas supply, solve the environmental problems caused by coal combustion and emission of $\mathrm{CO}_{2}$, reserve resources and technologies for the era of "hydrogen economy". It will open up a new way for the construction of China's "clean, low-carbon, safe and efficient" modern energy system ${ }^{[1]}$.

China has been conducting UCG test under natural conditions since 1958. After the 1980s, Professor Yu Li proposed a new UCG process of "long channel, large section, two-stage". In the middle and late 1990s, Chai Zhaoxi put forward the proposal of "gasification mine", and the tests carried out in several mining areas in Heilongjiang and Henan Province were also successful.

After the 21 st century, the technology of UCG in the world basically adopts oil and natural gas technology and syngas purification technology, which has achieved good results in improving the environment. In recent years, there are more than $50 \mathrm{UCG}$ pilot projects in the world. Many enterprises and universities in China have participated in UCG projects, and carried out site selection research, furnace type and process research, model test and numerical simulation test research of $\mathrm{UCG}^{[2]}$.

In 2006, ENN energy group began to cooperate with China University of mining and Technology (Beijing) to carry out the research and application of coal in situ gasification technology, and carried out the experimental research of "underground coal gasification technology without well" in Ulanqab, Inner Mongolia, China. The early test shows that the gasification agent injection tool is easy to burn and has high pressure drop. To solve this problem, in 2015, Jianghan Machinery Research Institute Limited Company of CNPC cooperated with ENN energy group to develop a set of coiled-tubing gasification coal mining equipment ${ }^{[3]}$, and two patents were formed ${ }^{[4-5]}$. At present, the UCG technology has been basically mature, but the industrialization progress is slow due to the influence of the process and tools ${ }^{[1]}$. The purpose of this paper is to provide reference for related research and promote the industrialization of UCG technology in China.

\footnotetext{
a Corresponding author: chenzhi@enpc.com.cn
} 


\section{Methods and Materials}

\subsection{Gasification coal mining technology with coiled tubing}

Coiled-tubing gasification coal mining equipment mainly includes: coiled tubing (CT) operation skid, multi well operation remote monitoring centre, wellhead lifting device and gasification agent injection tool ${ }^{[6]}$. Controlled injection point retreat gasification process is adopted to combine directional drilling and reverse combustion. As shown in figure 1, the vertical injection well and production well are drilled from the ground to the coal seam, and then the horizontal well is drilled from the injection well along the coal seam floor to intersect with the bottom of the production well to form a gasification channel. At the beginning of gasification, the monitoring centre controls the coiled tubing operation skid, uses the coiled tubing to place the injection tool along the injection well and the horizontal well downhole to the first injection point which near the production well, uses the igniter to ignite the coal at the first injection point, and the ground equipment injects air or oxygen and steam into the burning coal through the coiled tubing, so that the coal pyrolysis, oxidation and reduction occur. The gas produced by gasification reaction is led out from the production well. Low calorific value gas $\left(3.9\right.$ to $\left.6.3 \mathrm{MJ} / \mathrm{m}^{3}\right)$ can be produced by injecting air and steam, and medium calorific value gas $\left(8.2\right.$ to $11.0 \mathrm{MJ} / \mathrm{m}^{3}$ ) can be produced by injecting oxygen and steam. The ignited coal body burns all the way to the roof of the coal seam. After a section of coal body is burned, the coiled tubing pulls the injection tool back to the next injection point, and the combustion surface of the coal seam will advance towards the direction of the injection point back, forming a new combustion zone.

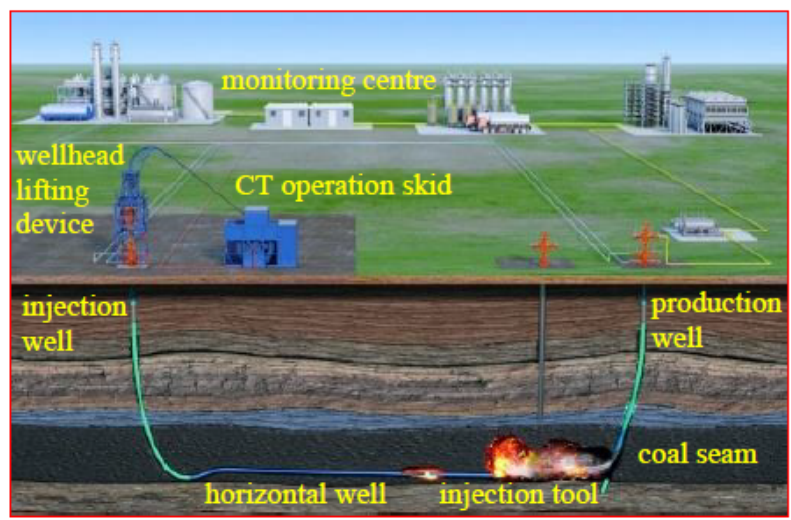

Figure 1. Schematic operation of the coiled tubing unit for coal gasification and mining.

\subsection{Tool structure}

Two kinds of gasification agent injection tools have been developed, including type I and type II. The structures are shown in figure 2 and figure 3 respectively. The thermocouple is installed in the front of the tool to transmit the temperature of the coal seam to the remote monitoring centre of multi well operation on the ground through the signal line, and the signal line is installed in the annulus between the coiled tubing and the water injection pipe.

\subsection{Working principle}

As shown in figure 2, when the type I gasification agent injection tool is working, oxygen is transported to the outer cylinder cavity through the annulus between the coiled tubing and the water injection pipe, and enters the inner cavity of the straight pipe through the shunt body. Under the action of oxygen pressure, the check valve plate is opened in the positive direction, and the mixed gas enters the inner cavity of the nozzle, and finally ejects through the nozzle. Through the water injection pipe, the water enters the annulus between the outer cylinder and the straight pipe through the shunt body, and finally ejects out through the hole in the front end of the nozzle. The ejected water and oxygen are mixed at the front end of the injection tool, and the ignited coal seam undergoes pyrolysis, reduction, oxidation and other gasification reactions to produce gas. When the gasification agent injection stops, the check valve plate reversely stops, which will prevent the high-temperature gas in the coal seam from flowing back into the tool and burn the tool, that is, to prevent backfire. The thermocouple installed in the injection tool is used to monitor the temperature near the injection point. The remote monitoring centre of multi well operation on the ground timely receives the temperature signal through the signal line, uses the temperature to judge the status and position of the coal seam combustion zone, and controls the injection tool to retreat through the coiled tubing to adjust the position of the injection point.

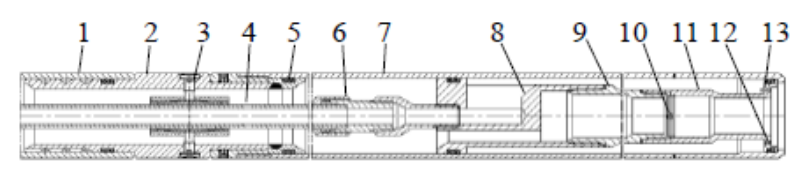

Figure 2. Structure diagram of type I gasification agent injection tool.

1 -coiled tubing; 2 -connector; 3 -centralizing support; 4 water injection pipe; 5-seal; 6-quick connector; 7-outer cylinder; 8-shunt body; 9-straight pipe; 10—check valve plate; 11-nozzle; 12-hole; 13-thermocouple

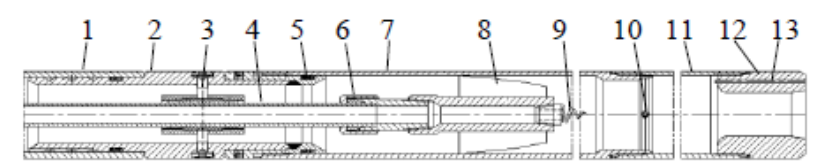

Figure 3. Structure diagram of type II gasification agent injection tool.

1 -coiled tubing; 2 -connector; 3 -centralizing support; $4-$ water injection pipe; 5-seal; 6-quick connector; 7-outer cylinder; 8-swirling body; 9-atomizing nozzle; 10-check valve plate; 11 -lower cylinder; 12 -nozzle; 13 -thermocouple

As shown in figure 3, when the type II gasification agent injection tool works, oxygen is transported to the outer cylinder cavity through the annulus between the coiled tubing and the water injection pipe, and the rotating oxygen flow is formed through the swirling action of the swirling body; water is transported to the front end of the atomizing nozzle through the water injection pipe for atomization. The atomized water and rotating oxygen flow are mixed in the cavity at the right end of the outer cylinder. 
Under the effect of oxygen pressure, the check valve plate is opened in the positive direction, and the mixed gas enters the lower cylinder. Finally, the mixed gas is ejected through the nozzle, and gasification reactions such as pyrolysis, reduction and oxidation occur with the ignited coal seam to produce gas. This type of tool is also designed with check valve plate and thermocouple, and its function and installation method are the same as that of type I tool.

\subsection{Main technical features}

This paper introduces two kinds of gasification agent injection tools, through thermocouple, signal line and monitoring centre, timely monitor the working condition of coal seam combustion zone, and control the appropriate distance between the injection point and the combustion zone, so as to ensure that the tools can work normally and avoid being burned. In view of the situation of easy to burn out in backfire, an backfire prevention device is designed. By optimizing the structure and material selection, the tool also has the characteristics of low pressure drop and high temperature resistance. In addition, when the type I gasification agent injection tool is working, because the interlayer between the outer cylinder and the inner cylinder will have injected water flow through, it has a good cooling effect on the outer cylinder of the tool, and can protect the tool from being burned by underground high temperature. Type II gasification agent injection tool is equipped with atomizing nozzle and swirling body. The atomizing nozzle makes the injected water form water mist, and the swirling body turns the input oxygen into swirling air flow, which is fully mixed with water mist, which is conducive to the completion of gasification reaction. Water mist is also beneficial to reduce the temperature of tools and prevent them from being burned.

\subsection{Key technology}

UCG gasifier injection tool requirements: oxygen flow rate is $2000 \mathrm{~m}^{3} / \mathrm{h}$, gas pressure drop is no more than 0.5 $\mathrm{MPa}$, well depth is $300 \mathrm{~m}$, bottom hole pressure is $1.5 \mathrm{MPa}$. Due to the large gas transmission capacity, it is necessary to check the gas pressure drop of the tool, which is introduced.

\subsubsection{Verification of pressure drop $\Delta p_{s q}$ of type I tools}

As shown in figure 2, the pressure drop of type I gasification agent tool is composed of the sum of the pressure drop of nozzle and straight pipe. Firstly, check the gas pressure drop in the nozzle section. According to reference ${ }^{[6]}$. the calculation formula of flow pressure difference of variable cross-section pipe is

$$
\dot{m}=\rho_{0}\left(2 C_{\mathrm{p}} T\right)^{\frac{1}{2}} A\left(\frac{P}{P_{0}}\right)^{\frac{1}{\kappa}}\left[1-\left(\frac{p}{p_{0}}\right)^{\frac{\kappa-1}{\kappa}}\right]^{\frac{1}{2}}
$$

The constant pressure specific heat capacity of ideal gas is

$$
C_{\mathrm{p}}=\kappa R(\kappa-1)^{-1}
$$

The Clapeyron equation is

$$
p=\rho R T
$$

According to equation (3), the density of inlet oxygen is

$$
\rho_{0}=p_{0}(R T)^{-1}
$$

By substituting equations (2) and (4) into equation (1), and then square the two ends of equation (1), we can get

$$
\dot{m}^{2}=\left(\frac{p_{0}}{R T}\right)^{2}\left(2 \frac{\kappa}{\kappa-1} R T\right) A^{2}\left(\frac{p}{p_{0}}\right)^{\frac{2}{\kappa}}\left[1-\left(\frac{p}{p_{0}}\right)^{\frac{\kappa-1}{\kappa}}\right]
$$

Continue to deduce, you can get

$$
\frac{\dot{m}^{2} R T(\kappa-1)}{2 A^{2} \kappa}=p^{\frac{2}{\kappa}} p_{0}^{\frac{2 \kappa-2}{\kappa}}-p^{\frac{\kappa+1}{\kappa}} p_{0}^{\frac{\kappa-1}{\kappa}}
$$

Where

$\dot{m}$ - oxygen mass flow rate, at $25{ }^{\circ} \mathrm{C}$, standard atmospheric pressure, oxygen density $\rho=1.292 \mathrm{~kg} / \mathrm{m}^{3}$, $\dot{m}=\rho Q=0.718 \mathrm{~kg} / \mathrm{s}$;

$R$ - oxygen gas constant, $\mathrm{j} /(\mathrm{kg} \cdot \mathrm{K})$, the value is $259.7 \mathrm{j} /(\mathrm{kg} \cdot \mathrm{K})$;

$T$ - bottom hole temperature, $\mathrm{K}$, the value is $307 \mathrm{~K}$;

$\kappa$ - adiabatic index, the value is 1.4 ;

$A$ - sectional area of nozzle, $\mathrm{mm}^{2}$, the value is $530.929 \mathrm{~mm}^{2}$;

$p_{0}$ - oxygen pressure at inlet of nozzle section, MPa;

$p$ - oxygen pressure at outlet of nozzle section, that is bottom hole pressure, the value is $1.5 \mathrm{MPa}$.

By substituting the parameters into equation (5) and using Maple 10 for calculation, the numerical solution of inlet oxygen pressure can be obtained. The calculation code and results are as follows.

$>$ solve $\left(1.5^{\wedge}(2 / 1.4)^{*} \mathrm{p} 0^{\wedge}(4 / 7)-1.5^{\wedge}(2.4 / 1.4)^{*} \mathrm{p} 0^{\wedge}(2 / 7)-\right.$ $\left.0.718^{\wedge} 2^{*} 259.7 * 307 *(1.4-1) /\left(530.929^{\wedge} 2 * 2 * 1.4\right), \mathrm{p} 0\right)$;

1.548716210

Take $p_{0}=1.5487 \mathrm{MPa}$.

Check the gas pressure drop of straight pipe section. Reference $^{[6]}$ shows that the Mach number at the straight pipe inlet is

$$
M=\frac{\dot{m}(R T)^{\frac{1}{2}}}{p A_{1} \kappa^{\frac{1}{2}}}
$$

In this scheme, the gas flow rate is low and it is in thermal equilibrium with the surrounding medium, so it can be regarded as isothermal flow. According to reference ${ }^{[6]}$, the calculation formula of pressure difference of isothermal pipe flow is

$$
\frac{\mathrm{d} p}{p}=-\frac{\kappa M^{2}}{2\left(1-\kappa M^{2}\right)} f \frac{\mathrm{d} x}{D}
$$

By substituting equation (7) into equation (8), simplifying and integrating the two ends, we can get

$$
\frac{A_{1}^{2}}{2 \dot{m}^{2} R T}\left(p_{0}^{2}-p_{1}^{2}\right)-\ln p_{0}+\ln p_{1}=-\frac{f}{2 D}\left(x_{0}-x_{1}\right)
$$

Where

$A_{1}$ - sectional area of straight pipe, $\mathrm{mm}^{2}$, the value is $754.4 \mathrm{~mm}^{2}$; 
$D$ - equivalent diameter of flow passage, $\mathrm{mm}$, the value is $31 \mathrm{~mm}$;

$p_{0}$ - oxygen pressure at outlet of straight pipe section, that is oxygen pressure at inlet of nozzle section, the value is $1.5487 \mathrm{MPa}$;

$p_{1}-$ oxygen pressure at inlet of straight pipe section, $\mathrm{MPa}$;

$x_{0}$ - the position coordinate along the flow direction at the inlet of nozzle section (outlet of straight pipe section), $x_{1}$ is the position coordinate along the flow direction at the inlet of straight pipe section, and the difference between $x_{0}$ and $x_{1}$ is the length of straight pipe section, taking $1500 \mathrm{~mm}$;

$f-$ friction coefficient of fluid, the value is 0.02 .

By substituting the parameters into equation (9) and using Maple 10 for calculation, the numerical solution of inlet oxygen pressure can be obtained. The calculation code and results are as follows.

$>$ solve $\left(\mathrm{Pi}^{\wedge} 2 * 31^{\wedge} 4 /\left(32 * 0.718^{\wedge} 2 * 259.7 * 307\right) *(1.5487\right.$ $\left.\wedge 2-\mathrm{p} 1 \wedge 2)-\ln (1.5487)+\ln (\mathrm{p} 1)=-0.02 /(2 * 31)^{*} 1500, \mathrm{p} 1\right)$;

$$
0.5769931134 \quad 10^{-7}, \quad 1.571758998
$$

According to the actual situation, the inlet pressure should be greater than the outlet pressure, $p_{0}=1.5487 \mathrm{mpa}$, so $p_{1}=1.5718 \mathrm{MPa}$. The total pressure drop $\Delta p_{\mathrm{sq}}=p_{1}-p$ $=0.0718 \mathrm{MPa}$, less than $0.5 \mathrm{MPa}$, which meets the use requirements.

\subsubsection{Verification of pressure drop $\Delta p_{z q}$ of type II tools.}

As shown in figure 3, the pressure drop of type II tool is composed of the pressure drop of nozzle and swirling flow passage, and the swirling flow section is simplified as a circular flow passage. Referring to the calculation method of type I tool mentioned above, substituting the design parameters into equation (6) and equation (9) respectively, and using Maple 10 for calculation, the numerical solution of oxygen pressure at the inlet of nozzle section $p_{0}$ $=1.5275 \mathrm{MPa}$ and that of swirl section $p_{1}=1.5315 \mathrm{MPa}$ can be obtained. The total pressure drop of the tool is $\Delta$ $p_{\text {zq }}=p_{1}-p=0.0315 \mathrm{MPa}$, less than $0.5 \mathrm{MPa}$, which meets the use requirements.

\section{Results \& Discussion}

The tool needs to bear a certain load when lifting and lowering the string and working, and works for a long time in pure oxygen environment. During the design and trial production, 309S is selected as the main component material, which has good oxidation resistance, corrosion resistance and high temperature strength. 304 or $316 \mathrm{~L}$ is selected for other parts. Due to the pressure in the process of gasification agent injection, the joints between the parts need to be sealed. The radial seal uses the flexible graphite braided packing (RBTN2-600) which can withstand $600{ }^{\circ} \mathrm{C}$, and the axial seal uses 304 stainless steel metal gasket, which has good corrosion resistance and oxidation resistance. The service temperature is -196 to $800{ }^{\circ} \mathrm{C}$. When installing the metal gasket, evenly apply high temperature resistant sealant $\left(-80\right.$ to $1280{ }^{\circ} \mathrm{C}$ ) on both sides of the gasket to ensure reliable sealing.

After the tool is manufactured, the gas pressure drop test was carried out in Ulanqab City, Inner Mongolia, China from December 1 to 7, 2015. There are 7 groups of air pumps, and the maximum total output flow is 2100 $\mathrm{m}^{3} / \mathrm{h}$. The test site is shown in figure 4 and figure 5 .

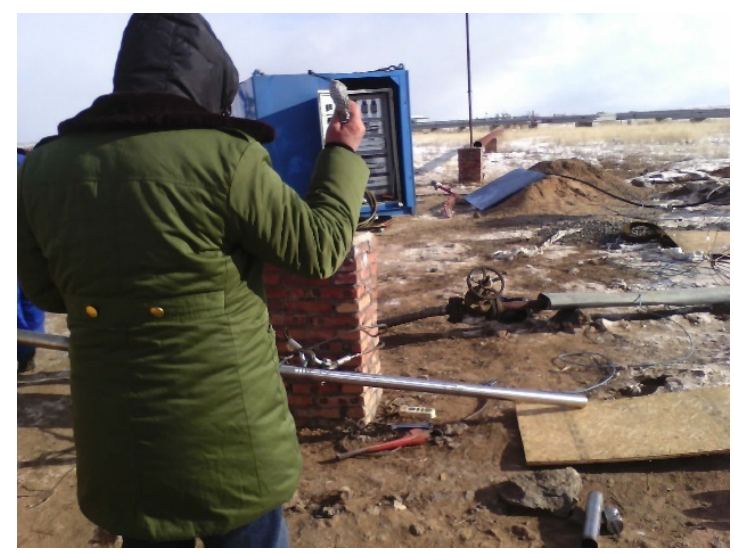

Figure 4. Ground pressure drop test.

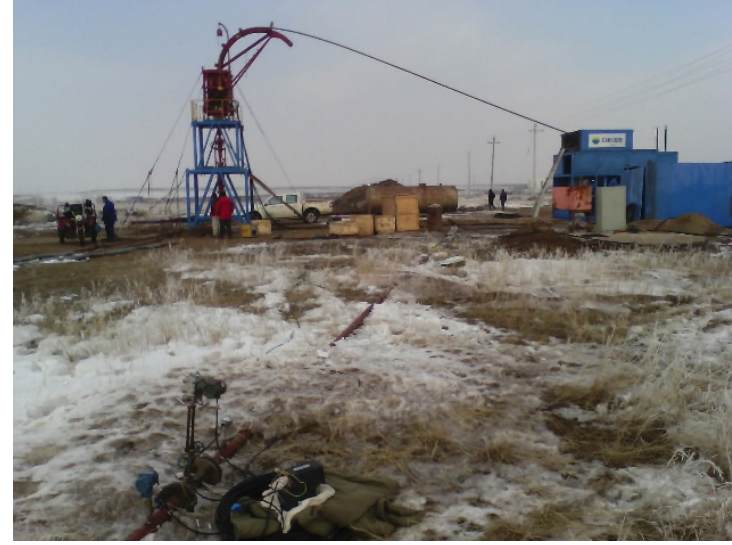

Figure 5. System pressure drop test after running in well

The test is divided into two stages, the first is the ground pressure drop test, the test results: when the total output flow of the air pumps is 1833 to $1866 \mathrm{~m}^{3} / \mathrm{h}$, the type I tool gas pressure drop $\Delta p=0.07 \mathrm{MPa}$, which is basically consistent with the design check value of $0.0718 \mathrm{MPa}$; the type II tool gas pressure drop $\Delta p=0.04 \mathrm{MPa}$, which is slightly larger than the design value of $0.0315 \mathrm{MPa}$. Both tools meet the requirements of gas pressure drop, less than $0.5 \mathrm{MPa}$. Then, using the coiled tubing run the type I tool downhole for $50 \mathrm{~m}$, and five groups of data are tested. The test results are shown in table 1 . The pressure drop of the equipment system is 0.85 to $1.08 \mathrm{MPa}$, less than $3 \mathrm{MPa}$, which meets the use requirements.

Table 1. System pressure drop of coiled tubing and type I tool.

\begin{tabular}{|c|c|c|c|}
\hline $\begin{array}{c}\text { Air pump } \\
\text { displacement. } \\
\mathbf{( m}^{\mathbf{3}} \cdot \mathbf{h}^{-\mathbf{1}} \mathbf{)}\end{array}$ & $\begin{array}{c}\text { Inlet } \\
\text { pressure. } \\
(\mathbf{M P a})\end{array}$ & $\begin{array}{c}\text { Outlet } \\
\text { pressure. } \\
(\mathbf{M P a})\end{array}$ & $\begin{array}{c}\text { System } \\
\text { pressure drop. } \\
(\mathbf{M P a})\end{array}$ \\
\hline $1833 \sim 1866$ & 2.08 & 1.0 & 1.08 \\
\hline $1833 \sim 1866$ & 2.14 & 1.1 & 1.04 \\
\hline $1833 \sim 1866$ & 2.20 & 1.2 & 1.0 \\
\hline $1833 \sim 1866$ & 2.19 & 1.3 & 0.89 \\
\hline $1833 \sim 1866$ & 2.25 & 1.4 & 0.85 \\
\hline
\end{tabular}




\section{Conclusions}

1. Two kinds of UCG gasifier injection tools solve the problem of uncontrolled injection point through the joint work of downhole temperature measurement and ground monitoring.

2. Through the design of backfire prevention device, the problem of tool being burnt by the backfire is solved. According to the requirement of low pressure drop, the structure of gasification agent flow channel in the tool is optimized, so that the pressure drop of the tool is less than $0.5 \mathrm{MPa}$ and that of the system is less than $3 \mathrm{MPa}$.

3. The tool overall has the functional characteristics of low pressure drop, high temperature resistance, backfire prevention and anti burning to satisfy the demand of the field test.

4. The two kinds of UCG gasification injection tools are a new achievement of UCG equipment development in China. The successful development of the tools can provide technical reference for the development of new generation UCG technology.

\section{Acknowledgments}

This paper is one of the phased achievements of the project "research and application of underground gasification well operation equipment" (No.: 2019E-2504) of PetroChina.

We thank the managements of Jianghan Machinery Research Institute Limited Company of CNPC for permission to publish this paper. We also thank all those who helped assemble and produce the documentation.

\section{References}

1. ZOU C N, CHEN Y P, KONG L F, et al. (2019) Underground coal gasification and its strategic significance to the development of natural gas industry in China. Petroleum Exploration and Development, 46(2): 1-10.

2. LIU N N, QIU L L, JING Y. (2009) Present development of underground coal gasification (UCG) both in China and abroad. Coal Technology, 28(6): 57.

3. ZHANG F Q, LIU S J,SHAO C Q, et al. (2016) Development of integrated control coiled tubing unit for gasification coal mining. China Petroleum Machinery, 44(9): 75-79.

4. Jianghan Machinery Research Institute of Drilling Engineering Technology CNPC, Xin'ao Gasification Coal Mining Co. LTD. (2015) The utility model relates to central water-pipe type gasification coal mining device: ZL201510647968.8[P].

5. Xin'ao Gasification Coal Mining Co. LTD, Jianghan Machinery Research Institute of Drilling Engineering Technology CNPC. (2015) A nozzle and an air injection device having the nozzle: ZL201510765766.3[P].

6. CHEN W M. (1995) Fundamentals offluid mechanics. Beijing: Chemical Industry Press. 